\title{
NOTE
}

\section{Analysis of Glucosylceramides from Various Sources by Liquid Chromatography-Ion Trap Mass Spectrometry}

\author{
Tatsuya Sugawara ${ }^{1 *}$, Kazuhiko Aida ${ }^{2}$, Jingjing Duan ${ }^{1}$ and Takashi Hirata ${ }^{1}$ \\ ${ }^{1}$ Division of Applied Biosciences, Graduate School of Agriculture, Kyoto University (Sakyo-ku, Kyoto, Kyoto 606-8502, JAPAN). \\ ${ }^{2}$ Central Laboratory, Nippon Flour Mills Co., Ltd. (Atsugi, Kanagawa 243-0041, JAPAN)
}

\begin{abstract}
Liquid chromatography-mass spectrometry is one of the most powerful methods for the identification and detection of chemical structures of lipids. In this study, we attempted to identify the chemical structures of glucosylceramides from maize, rice, mushroom (maitake) and sea cucumber by liquid chromatography-ion trap mass spectrometry. For structural analysis of glucosylceramides, $[\mathbf{M}+\mathbf{H}]^{+},[\mathbf{M}+\mathbf{H}-18]^{+}$ or $[\mathrm{M}+\mathrm{H}-162]^{+}$in the positive scan mode was used for MS/MS analysis to obtain product ion spectra. The typical signals which are characteristic for the sphingoid base moieties were observed while the isomers could not be distinguished. This method should be useful for the structural determination of diverse glucosylceramide molecular species.
\end{abstract}

Key words: liquid chromatography-ion trap mass spectrometry, glucosylceramide, chemical structures of lipids

\section{INTRODUCTION}

Dietary sphingolipids have gained attention for their potential to protect intestine from inflammation and cancers ${ }^{1-4)}$. One plausible mechanism for these effects is believed to be via the hydrolysis of complex sphingolipids to bioactive ceramides and sphingoid bases, because those breakdown products play important roles as intracellular mediators ${ }^{5,6)}$. Our previous findings indicated that sphingoid bases prepared from dietary sources can induce apoptosis in colon cancer cell lines ${ }^{7-9)}$, and dietary sphingolipids from plant and yeast prevent the formation of aberrant crypt foci in 1 , 2-dimethylhydrazine-treated mice ${ }^{10,11)}$. In addition, other physiological functions of sphingolipids, such as improving the barrier function of skin, lowering plasma lipids and preventing of melanin formation, have also been reported ${ }^{12-14}$.

Sphingolipids are ubiquitous in all eukaryotic organisms, and constitute a family of compounds that have a sphingoid base (long-chain base) with an amide-linked fatty acid and a polar head group. It is well known that there are diverse structures of sphingoid bases in nature ${ }^{15,16)}$. The most common sphingoid base of mammalian sphingolipids is sphingosine (trans-4-sphingenine, $\mathrm{d} 18: 1^{4 \mathrm{t}}$ ). Smaller amounts of other sphingoid bases, such as sphinganine (dihydrosphingosine, d18:0) and phytosphingosine (4-hydroxysphinganine, t18:0) are frequently encountered. The structure of sphingoid bases in higher plants is more complicated than in mammals, because they can be desaturated at the C8position by a $\Delta 8$-sphingolipid desaturase, yielding $c i s$ - and trans- isomers of $\Delta 8$-unsaturated sphingoid bases (cis/ trans-8-sphingenine, d18:1 $1^{8 c t}$; trans-4, cis/trans-8-sphingadienine, d18:2 $2^{4 t, 8 c / t} ; 4$-hydrosy-cis/trans-8-sphingenine, $\left.\left.\mathrm{t} 18: 1^{8 / t}\right)^{17}\right)$. In fungi, 9-methyl-trans-4, trans-8-sphingadienine $\left(\mathrm{d} 19: 2^{4 t, 8 t}\right)$ is a typical structure ${ }^{16)}$. In addition, sphingolipids of marine invertebrates have unique triene types of sphingoid bases with a conjugated diene such as 2-amino-4, 8, 10-octatriene-1, 3-diol $\left(\mathrm{d} 18: 3^{4,8,10}\right)$ and 2-amino-9-methyl-4, 8, 10-octatriene-1, 3-diol $\left(\mathrm{d} 19: 3^{4,8,10}\right)^{18}$. Thus, sphingolipids having various structures of sphingoid bases are ingested daily from foodstuff. Determination of their diverse structures including variation of sphingoid backbone must be important for understanding the functional and nutritional significance of dietary sphingolipids.

Liquid chromatography-mass spectrometry is one of the

\footnotetext{
*Correspondence to: Tatsuya Sugawara, Graduate School of Agriculture, Kyoto University, Kyoto, Kyoto 606-8502, JAPAN

E-mail: sugawara@kais.kyoto-u.ac.jp

Accepted February 1, 2010 (received for review January 12, 2010)

Journal of Oleo Science ISSN 1345-8957 print / ISSN 1347-3352 online

http://www.jstage.jst.go.jp/browse/jos/
} 
most powerful methods for identification and detection of chemical structures of lipids including sphingolipids ${ }^{19,20)}$. In this study, we attempted to identify the structures of glucosylceramide(GluCer, Fig. 1), one of the predominant sphingoglycolipids, from various sources by liquid chromatography-ion trap mass spectrometry.

\section{EXPERIMENTAL}

\subsection{Materials}

GluCer were prepared from maize, rice, mushroom (maitake) and sea cucumber by a silica gel column after lipid extraction and saponification as described previously ${ }^{9,21)}$. All other chemicals and solvent were of reagent grade.

\subsection{LC-MS/MS analyses}

A prominence HPLC system coupled to LCMS-IT-TOF equipped with an electrospray ionization interface (Shimadzu, Kyoto, Japan) was used. For structural analysis of GluCer, $[\mathrm{M}+\mathrm{H}]^{+},[\mathrm{M}+\mathrm{H}-18]^{+}$(loss of water) or $[\mathrm{M}+\mathrm{H}-$ $162]^{+}$(loss of glucose) in the positive scan mode was used for MS/MS analysis to obtain the product ions. A TSK gel ODS-100Z column $(2.0 \times 50 \mathrm{~mm}, 3 \mu \mathrm{m}$, Tosoh, Tokyo, Japan)was eluted with acetonitrile/water $(95: 5, \mathrm{v} / \mathrm{v})$ at a flow rate of $0.2 \mathrm{~mL} / \mathrm{min}$. The MS was operated with the following conditions: probe voltage of $4.50 \mathrm{kV}$, CDL temperature of $200^{\circ} \mathrm{C}$, block heater temperature of $200^{\circ} \mathrm{C}$, nebulizer gas flow of $1.5 \mathrm{~L} / \mathrm{min}$, ion accumulation time of $100 \mathrm{msec}$, MS range of $\mathrm{m} / \mathrm{z} 650$ to $900, \mathrm{MS}^{2}$ range of $\mathrm{m} / \mathrm{z} 200$ to 300 , and CID parameters were follows: energy, $60 \%$; collision gas $60 \%$.

The typical signals which are characteristic for the sphingoid base moieties were observed by auto MS/MS detection mode in this system. The structures and characteristic product ions of diverse sphingoid bases contained in GluCer are given in Fig. 2. Pairs of these structurally specific ions of sphingoid bases and their precursor ions were used for the identification of GluCer molecules.

\section{RESULTS AND DISUCUSSION}

Figure 3 shows total ion and selected ion chromatograms of GluCer prepared from maize, and MS spectra of repre- sentative peaks. In the positive full scan mode, $[\mathrm{M}+\mathrm{Na}]^{+}$, $[\mathrm{M}+\mathrm{H}]^{+}$and $\left[\mathrm{M}+\mathrm{H}-\mathrm{H}_{2} \mathrm{O}\right]^{+}$were the predominant signals in each peak (Fig. 3). The transition of precursor ions $[\mathrm{M}+$ $\mathrm{H}]^{+}$and $\left[\mathrm{H}+\mathrm{H}-\mathrm{H}_{2} \mathrm{O}\right]^{+}$to the product ions of the sphingoid bases was used for the identification of GluCer molecular species (Table 1). Nine molecules were determined by pairs of specific product ions of sphingoid bases and their precursor ions. In the case of GluCer molecules consisting of 4-hydoroxy-8-sphingenine (t18:1), the loss of glucose[M $+\mathrm{H}-162]^{+}$was clearly detected and was used as precursor ion, because the product ions could not be detected from $[\mathrm{M}+\mathrm{H}]^{+}$. In addition, $\left[\mathrm{H}+\mathrm{H}-\mathrm{H}_{2} \mathrm{O}\right]^{+}$ion was not detected in this system. Detection of GluCer consisting of d18:2 and t18:1 was separated into two peaks, cis- and trans-isomers of $\Delta 8$-unsaturated sphingoid bases. Predominantly hydroxy fatty acids containing 16 to 26 carbon atoms were detected in maize GluCer. The present components of maize GluCer were in accordance with previous reports $^{10,22)}$.

The total ion chromatograms of GluCer from rice, maitake and sea cucumber are shown in Fig. 4. The patterns of chromatograms in the present HPLC condition were different among GluCer sources. Molecular structures of rice GluCer were similar to those of maize (Table 2). Molecular species of GluCer in rice consisted of hydroxy fatty acids with 18 to 26 carbon atoms including odd numbered fatty acid (C19:0h). Detection of molecules consisting of d18:2 and t18:1 in rice was separated into two peaks as similar as maize. In the case of GluCer with t18:1, the loss of glucose $[\mathrm{M}+\mathrm{H}-162]^{+}$was used as precursor ion (peaks 6,8 and 12 in Fig. 4). GluCer molecules consisting of d18:1 were also detected in this sample. It has been known that the major sphingoid backbone in fungal sphingolipids is a unique 9-methyl branched sphingoid base (9-methyl-4, 8 -sphingadienine, d19:2 ${ }^{16,23,24)}$. In this study, GluCer containing d19:2 acylated to hydroxy fatty acids with 14-24 carbon atoms were identified in maitake (Table 3). Odd numbered hydroxyl fatty acids (C15:0h and C17:0h)were also predominant. Sphingadienine (d18:2) acylated to C20:0h was found in GluCer from maitake. GluCer molecules consisting of d18:1 and non-hydroxy fatty acid were also detected. It has been reported that the sphingoid bases in marine invertebrates were quite different from those in mammals and plants ${ }^{9,18)}$. The product ions detected from sea cucumber GluCer were identified as d17:1, d18:1,



Fig. 1 Representative Structure of Glucosylceramide (D-Glucosyl- $\beta-1,1^{\prime}-\mathrm{N}-$ palmitoylsphingosine). 
<smiles>NC(CO)C(O)CCCCCCCCCCCCCCCCCCCCCCCCCCCCCCC(O)C(N)CO</smiles><smiles>CC(C)(C)CCCCOC(F)(F)CCCCCCCCCCCCCC(O)C(O)C(N)CO</smiles><smiles>CCCCCCCCCCC=CCCCCCC(O)C(N)CO</smiles>

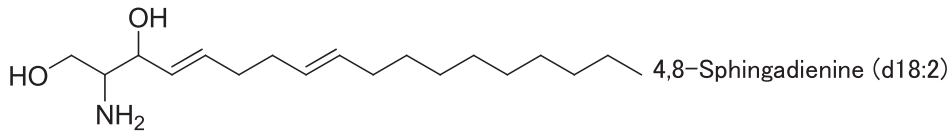





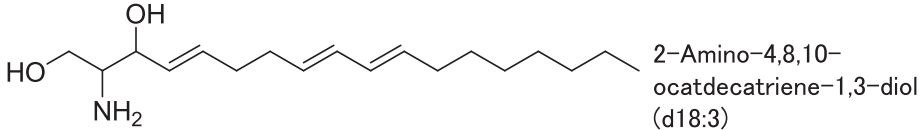

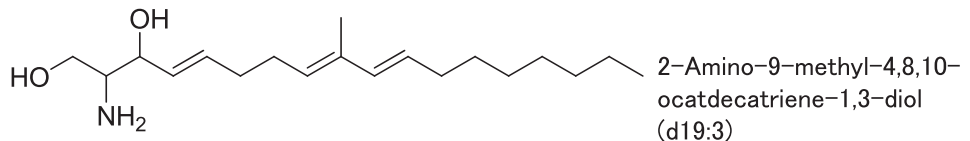

Typical product ion

$\mathrm{m} / \mathrm{z}=284.3$

$\left[\mathrm{M}+\mathrm{H}-\mathrm{H}_{2} \mathrm{O}\right]^{+}$

$\mathrm{m} / \mathrm{z}=264.3$

$\left[\mathrm{M}+\mathrm{H}-2 \mathrm{H}_{2} \mathrm{O}\right]^{+}$

$\left\{\begin{array}{l}\mathrm{m} / \mathrm{z}=282.3 \\ {\left[\mathrm{M}+\mathrm{H}-2 \mathrm{H}_{2} \mathrm{O}\right]^{+}} \\ \mathrm{m} / \mathrm{z}=264.3 \\ {\left[\mathrm{M}+\mathrm{H}-3 \mathrm{H}_{2} \mathrm{O}\right]^{+}}\end{array}\right.$

$\mathrm{m} / \mathrm{z}=264.3$

$\left[\mathrm{M}+\mathrm{H}-2 \mathrm{H}_{2} \mathrm{O}\right]^{+}$

$\mathrm{m} / \mathrm{z}=262.3$

$\left[\mathrm{M}+\mathrm{H}-2 \mathrm{H}_{2} \mathrm{O}\right]^{+}$

$\mathrm{m} / \mathrm{z}=280.3$
$\left[\mathrm{M}+\mathrm{H}-2 \mathrm{H}_{2} \mathrm{O}\right]^{+}$
$\mathrm{m} / \mathrm{z}=262.3$
$\left[\mathrm{M}+\mathrm{H}-3 \mathrm{H}_{2} \mathrm{O}\right]^{+}$

$\mathrm{m} / \mathrm{z}=276.3$

$\left[\mathrm{M}+\mathrm{H}-2 \mathrm{H}_{2} \mathrm{O}\right]^{+}$

$\mathrm{m} / \mathrm{z}=260.3$

$\left[\mathrm{M}+\mathrm{H}-2 \mathrm{H}_{2} \mathrm{O}\right]^{+}$

$\mathrm{m} / \mathrm{z}=274.3$

$\left[\mathrm{M}+\mathrm{H}-2 \mathrm{H}_{2} \mathrm{O}\right]^{+}$

Fig. 2 Structures and Characteristic Product Ions of Sphingoid Bases. The name and shorthand designations were described by Karlsson ${ }^{15)}$. M = m/z of each sphingoid base.

Table 1 Detection and Identification of Glucosylceramide Molecular Species from Maize by HPLC-MS/MS Analysis.

\begin{tabular}{|c|c|c|c|c|c|}
\hline \multirow{2}{*}{$\begin{array}{l}\text { Peak No. } \\
\text { in Fig. } 3\end{array}$} & \multicolumn{3}{|c|}{ Precursor ion $\mathrm{m} / \mathrm{z}$} & \multirow{2}{*}{$\begin{array}{c}\text { Product ion } \\
\mathrm{m} / \mathrm{z}\end{array}$} & \multirow[t]{2}{*}{ Species } \\
\hline & {$[\mathrm{M}+\mathrm{H}]^{+}$} & {$[\mathrm{M}+\mathrm{H}-18]^{+}$} & {$[\mathrm{M}+\mathrm{H}-162]^{+}$} & & \\
\hline 1 & 714.6 & 696.6 & & 262.3 & d18:2-C16:0h \\
\hline 2 & 742.6 & 724.6 & & 262.3 & d18:2-C18:0h \\
\hline 3 & 816.7 & & 654.6 & $280.3 \quad 262.3$ & t18:1-C22:0h \\
\hline 4 & 770.6 & 752.6 & & 262.3 & d18:2-C20:0h \\
\hline 5 & 844.7 & & 682.6 & 280.3262 .3 & $\mathrm{t} 18: 1-\mathrm{C} 24: 0 \mathrm{~h}$ \\
\hline 6 & 798.7 & 780.6 & & 262.3 & d18:2-C22:0h \\
\hline 7 & 826.7 & 808.7 & & 262.3 & d18:2-C24:0h \\
\hline 8 & 840.7 & 822.7 & & 262.3 & d18:2-C25:0h \\
\hline 9 & 854.7 & 836.7 & & 262.3 & $\mathrm{~d} 18: 2-\mathrm{C} 26: 0 \mathrm{~h}$ \\
\hline
\end{tabular}




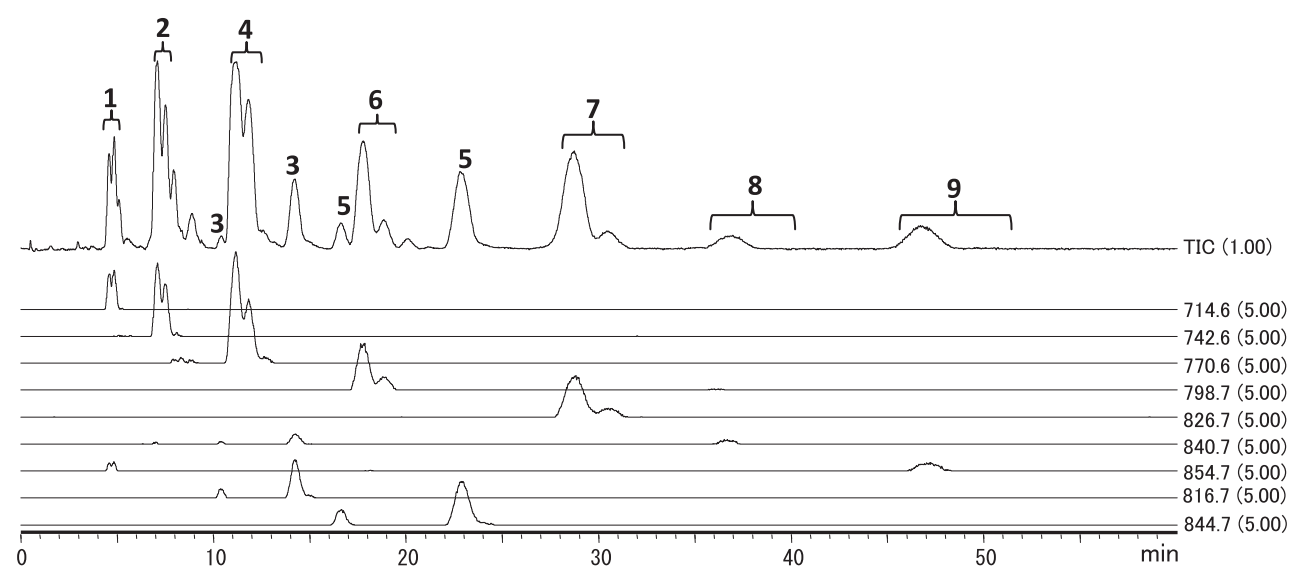

1. $\mathrm{d} 18: 2-16: 0 \mathrm{~h}$

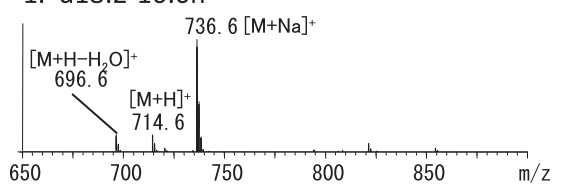

2. $\mathrm{d} 18: 2-18: 0 \mathrm{~h}$
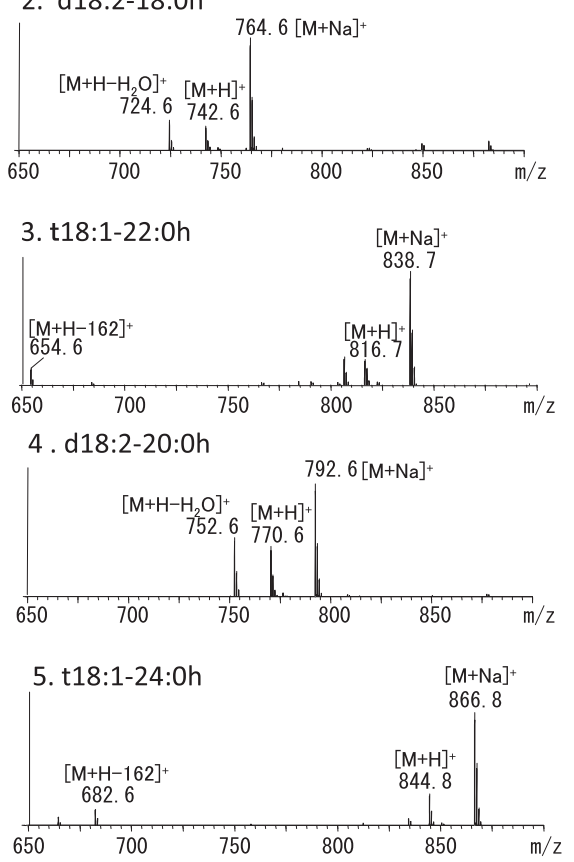

6. d18:2-22:0h

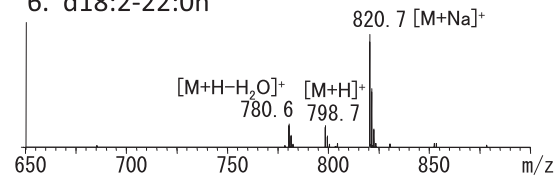

7. $\mathrm{d} 18: 2-24: 0 \mathrm{~h}$

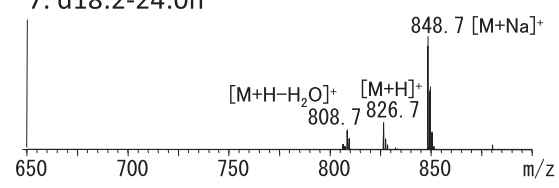

8. d18:2-25:0h
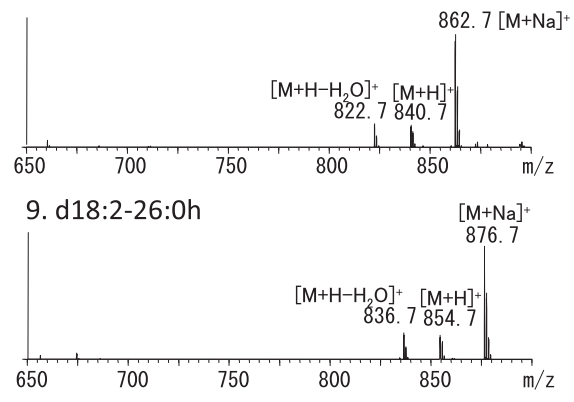

Fig. 3 Total Ion and Selected Ion Chromatograms of Maize Glucosylceramide and Mass Spectra of Peak Components.

d18:2, d18:3, d19:1, d19:2 and d19:3 in the present study (Table 4). This result was similar to the previous report ${ }^{9)}$. The fatty acid moieties of sea cucumber GluCer used in this study were mainly non-hydroxy fatty acids.

We previously reported that daily intake of plant-origin GluCer in Japan was estimated to be $50 \mathrm{mg}$ by their contents in foodstuff ${ }^{25)}$. Vesper et al. have summarized the amount of sphingolipids in food including dairy, meat and egg products, and estimated that sphingolipids consumption in United States was 300-400 mg/day ${ }^{26)}$. Yunoki et al. determined sphingolipid content in Japanese meals by us- ing HPLC-ELSD, and showed that total amounts of sphingolipids in typical high- and low-calorie meal were 128-292 $\mathrm{mg} /$ day and $45-81 \mathrm{mg} /$ day, respectively ${ }^{27)}$. Therefore, significant amounts of sphingolipids having various structures of sphingoid bases are ingested daily from foodstuff. Dietary sphingolipids consisted of sphingosine and sphinganine can be hydrolyzed to sphingoid bases, fatty acids and the polar head group by intestinal enzymes, and are then taken up by mucosal cells ${ }^{28,29)}$. However, a large portion of sphingosine is metabolized to fatty acids after absorption and a small part is resynthesized to complex sphingolipids ${ }^{30,31)}$. 



\section{Sea cucumber}



Fig. 4 Total Ion Chromatograms of Glucosylceramides from Rice (A), Maitake (B) and Sea Cucumber (C).

Table 2 Detection and Identification of Glucosylceramide Molecular Species from Rice by HPLC-MS/MS Analysis.

\begin{tabular}{cccccc}
\hline $\begin{array}{c}\text { Peak No. } \\
\text { in Fig. } 4\end{array}$ & \multicolumn{3}{c}{ Precursor ion m/z } & $\begin{array}{c}\text { Product ion } \\
\mathrm{m} / \mathrm{z}\end{array}$ & Species \\
\cline { 2 - 4 }$\left[\begin{array}{cccc}{[\mathrm{M}+\mathrm{H}]^{+}} \\
{[\mathrm{M}+\mathrm{H}-18]^{+}}\end{array}\right.$ & {$[\mathrm{M}+\mathrm{H}-162]^{+}$} & 262.3 & $\mathrm{~d} 18: 2-\mathrm{C} 16: 0 \mathrm{~h}$ \\
2 & 714.6 & 696.6 & & 262.3 & $\mathrm{~d} 18: 2-\mathrm{C} 18: 1 \mathrm{~h}$ \\
3 & 740.6 & 722.6 & & 262.3 & $\mathrm{~d} 18: 2-\mathrm{C} 18: 0 \mathrm{~h}$ \\
4 & 742.6 & 724.6 & & 262.3 & $\mathrm{~d} 18: 2-\mathrm{C} 19: 0 \mathrm{~h}$ \\
5 & 756.6 & 738.6 & & 262.3 & $\mathrm{~d} 18: 2-\mathrm{C} 20: 0 \mathrm{~h}$ \\
6 & 770.6 & 752.6 & & 280.3262 .3 & $\mathrm{t} 18: 1-\mathrm{C} 22: 0 \mathrm{~h}$ \\
7 & 816.7 & & 654.6 & 264.2 & $\mathrm{~d} 18: 1-\mathrm{C} 20: 0 \mathrm{~h}$ \\
8 & 772.6 & 754.6 & & 280.3262 .3 & $\mathrm{t} 18: 1-\mathrm{C} 24: 0 \mathrm{~h}$ \\
9 & 844.7 & & 682.6 & 262.3 & $\mathrm{~d} 18: 2-\mathrm{C} 22: 0 \mathrm{~h}$ \\
10 & 798.7 & 780.6 & & 262.3 & $\mathrm{~d} 18: 2-\mathrm{C} 24: 0 \mathrm{~h}$ \\
11 & 726.7 & 808.7 & & 264.3 & $\mathrm{~d} 18: 1-\mathrm{C} 23: 0$ \\
12 & 872.7 & 780.6 & & 280.3262 .3 & $\mathrm{t} 18: 1-\mathrm{C} 26: 0 \mathrm{~h}$ \\
13 & 812.7 & 794.7 & & 264.3 & $\mathrm{~d} 18: 1-\mathrm{C} 24: 0$ \\
\hline
\end{tabular}


Table 3 Detection and Identification of Glucosylceramide Molecular Species from Maitake by HPLC-MS/MS Analysis.

\begin{tabular}{|c|c|c|c|c|}
\hline \multirow{2}{*}{$\begin{array}{l}\text { Peak No. } \\
\text { in Fig. } 4\end{array}$} & \multicolumn{2}{|c|}{ Precursor ion $\mathrm{m} / \mathrm{z}$} & \multirow{2}{*}{$\begin{array}{c}\text { Product ion } \\
\mathrm{m} / \mathrm{z}\end{array}$} & \multirow[t]{2}{*}{ Species } \\
\hline & {$[\mathrm{M}+\mathrm{H}]^{+}$} & {$[\mathrm{M}+\mathrm{H}-18]^{+}$} & & \\
\hline 1 & 700.6 & 682.6 & 276.3 & d19:2-C14:0h \\
\hline 2 & 714.6 & 696.6 & 276.3 & d19:2-C15:0h \\
\hline 3 & 728.6 & 710.6 & 276.3 & d19:2-C16:0h \\
\hline 4 & 742.6 & 724.6 & 276.3 & d19:2-C17:0h \\
\hline 5 & 756.6 & 738.6 & 276.3 & d19:2-C18:0h \\
\hline 6 & 770.6 & 752.5 & 262.3 & d18:2-C20:0h \\
\hline 7 & 784.6 & 766.6 & 276.3 & d19:2-C20:0h \\
\hline 8 & 784.6 & 766.6 & 264.3 & d18:1-C22:0 \\
\hline 9 & 840.7 & 822.7 & 276.3 & d19:2-C24:0h \\
\hline 10 & 812.7 & 794.7 & 264.3 & d18:1-C24:0 \\
\hline
\end{tabular}

Table 4 Detection and Identification of Glucosylceramide Molecular Species from Sea Cucumber by HPLC-MS/MS Analysis.

\begin{tabular}{|c|c|c|c|c|}
\hline \multirow{2}{*}{$\begin{array}{l}\text { Peak No. } \\
\text { in Fig. } 4\end{array}$} & \multicolumn{2}{|c|}{ Precursor ion $\mathrm{m} / \mathrm{z}$} & \multirow{2}{*}{$\begin{array}{c}\text { Product ion } \\
\mathrm{m} / \mathrm{z}\end{array}$} & \multirow[t]{2}{*}{ Species } \\
\hline & {$[\mathrm{M}+\mathrm{H}]^{+}$} & {$[\mathrm{M}+\mathrm{H}-18]^{+}$} & & \\
\hline 1 & 728.6 & 710.6 & 276.3 & d19:2-C16:0h \\
\hline 2 & 724.6 & 706.6 & 260.3 & d18:3-C18:0 \\
\hline 3 & 754.6 & 736.6 & 274.3 & d19:3-C18:0h \\
\hline 4 & 700.6 & 682.6 & 264.3 & d18:1-C18:0 \\
\hline 5 & 738.6 & 720.6 & 274.3 & d19:3-C19:0 \\
\hline 6 & 726.6 & 708.5 & 262.3 & d18:2-C18:0 \\
\hline 7 & 808.7 & 790.7 & 274.3 & d19:3-C23:0 \\
\hline 8 & 784.6 & 766.6 & 250.3 & d17:1-C23:0 \\
\hline 9 & 822.7 & 804.7 & 274.3 & d19:3-C24:0 \\
\hline 10 & 822.7 & 804.7 & 260.3 & d18:3-C25:0 \\
\hline 11 & 798.7 & 780.6 & 250.3 & $\mathrm{~d} 17: 1-\mathrm{C} 24: 0$ \\
\hline 12 & 836.7 & 818.7 & 274.3 & d19:3-C25:0 \\
\hline 13 & 812.7 & 794.7 & 250.3 & $\mathrm{~d} 17: 1-\mathrm{C} 25: 0$ \\
\hline 14 & 826.7 & 808.7 & 264.3 & d18:1-C25:0 \\
\hline 15 & 800.7 & 782.6 & 250.3 & $\mathrm{~d} 17: 1-\mathrm{C} 23: 0 \mathrm{~h}$ \\
\hline 16 & 840.7 & 822.7 & 278.3 & d19:1-C25:0 \\
\hline 17 & 814.7 & 796.7 & 250.3 & d17:1-C24:0h \\
\hline 18 & 812.7 & 794.5 & 264.3 & $\mathrm{~d} 18: 1-\mathrm{C} 24: 0$ \\
\hline
\end{tabular}

We previously investigated the digestion and absorption of plant-derived sphingolipids and our finding indicated that the metabolic fate of plant-derived sphingoid bases, such as 4, 8-sphingadienine, within enterocytes differs from that of sphingosine ${ }^{21)}$. Sphingoid bases, except for sphingosine, appear to be transported out of cells across the apical membranes of enterocytes by P-glycoprotein after absorp- tion and consequently the intestinal uptake is quite poor ${ }^{32)}$, although the exact fate of dietary plant-derived sphingolipids is still not well understood. Thus, determination of sphingolipid structures including variation of sphingoid backbone from dietary sources is important for understanding their functional and nutritional significance.

In this study, we analyzed the chemical structures of 
GluCer from maize, rice, maitake and sea cucumber by liquid chromatography-ion trap mass spectrometry. Various molecules of GluCer were able to be identified using this system. However, quantitative analysis of each molecule of glucosylceramide should be difficult because each standard molecule is required in LC-MS/MS system. It could be concluded from the present results that MS/MS analysis is a powerful method for identification of molecular structures of sphingolipids from various sources.

\section{ACKNOWLEDGEMENT}

This work was supported by the Program for Promotion and Applied Researches for Innovations in Bio-oriented Industry (BRAIN).

\section{References}

1. Duan, R. D.; Nilsson, A. Metabolism of sphingolipids in the gut and its relation to inflammation and cancer development. Prog. Lipid Res. 4, 62-72(2009).

2. Schmelz, E. M. Sphingolipids in the chemoprevention of colon cancer. Front Biosci. 9, 2632-2639 (2004).

3. Schmelz, E. M.; Sullards, M. C.; Dillehay, D. L.; Merrill, A. H., Jr. Colonic cell proliferation and aberrant crypt formation are inhibited by dietary glycosphingolipids in 1, 2-dimethylhydrazine-treated CF1 mice. J. Nutr. 130, 522-527 (2000).

4. Schmelz, E. M.; Roberts, P. C.; Kustin, E. M.; Lemonnier, L. A.; Sullards, M. C.; Dillehay, D. L.; Merrill, A. H., Jr. Modulation of intracellular $\beta$-catenin localization and intestinal tumorigenesis in vivo and in vitro by sphingolipids. Cancer Res. 61, 6723-6729 (2001).

5. Hannun, Y. A.; Obeid, L. M. Principles of bioactive lipid signaling: lessons from sphingolipids. Nat. Rev. Mol. Cell Biol. 9, 139-150 (2008).

6. Cuvillier, O. Sphingosine in apoptosis signaling. Biochim. Biophys. Acta 1585, 153-162(2002).

7. Sugawara, T.; Kinoshita, M.; Ohnishi, M.; Miyazawa, T. Apoptosis induction by wheat-flour sphingoid bases in DLD-1 human colon cancer cells. Biosci. Biotechnol. Biochem. 66, 2228-2231 (2002).

8. Aida, K.; Kinoshita, M.; Sugawara, T.; Ono, J.; Miyazawa, T.; Ohnishi, M. Apoptosis inducement by plant and fungus sphingoid bases in human colon cancer cells. $J$. Oleo Sci. 53, 503-510(2004).

9. Sugawara, T.; Zaima, N.; Yamamoto, A.; Sakai, S.; Noguchi, R.; Hirata, T. Isolation of sphingoid bases of sea cucumber cerebrosides and their cytotoxicity against human colon cancer cells. Biosci. Biotechnol. Biochem. 70, 2906-2912(2006).

10. Aida, K.; Kinoshita, M.; Tanji, M.; Sugawara, T.; Tamu- ra, M.; Ono, J.; Ueno, N.; Ohnishi, M. Prevention of aberrant crypt foci formation by dietary maize and yeast cerebrosides in 1, 2-dimethylhydrazine-treated mice. J. Oleo Sci. 54, 45-49(2005).

11. Kinoshita, M.; Aida, K.; Tokuji, Y.; Sugawara, T.; Ohnishi, M. Effects of dietary plant cerebroside on gene expression in the large intestine of 1, 2-dimethylhydrazine (DMH) -treated mice determined by DNA microarray analysis. J. Food Lipids 16, 200-208(2009).

12. Tsuji, K.; Mitsutake, S.; Ishikawa, J.; Takagi, Y.; Akiyama, M.; Shimizu, H.; Tomiyama, T.; Igarashi, Y. Dietary glucosylceramide improves skin barrier function in hairless mice. J. Dermatol. Sci. 44, 101-107(2006).

13. Duivenvoorden, I.; Voshol, P. J.; Rensen, P. C.; van Duyvenvoorde, W.; Romijn, J. A.; Emeis, J. J.; Havekes, L. M.; Nieuwenhuizen, W. F. Dietary sphingolipids lower plasma cholesterol and triacylglycerol and prevent liver steatosis in APOE*3Leiden mice. Am. J. Clin. Nutr. 84, 312-321 (2006).

14. Kinoshita, M.; Hori, N.; Aida, K.; Sugawara, T.; Ohnishi, M. Prevention of melanin formation by yeast cerebroside in B16 mouse melanoma cells. J. Oleo Sci. 56, 645-648 (2007).

15. Karlsson, K. A. Sphingolipid long chain bases. Lipids 5, 878-891 (1970).

16. Sperling, P.; Heinz, E. Plant sphingolipids: structural diversity, biosynthesis, first gene and functions. Biochim, Biophys. Acta 1632, 1-15(2003).

17. Sperling, P.; Libish, B.; Zähringer, U.; Napier, J.N.; Heinz, E. Functional identification of a $\Delta 8$-sphingolipid desaturase from Borago officinails. Arch. Biochem. Biophys. 388, 293-298(2001).

18. Ohashi, Y.; Tanaka, T.; Akashi, S.; Morimoto, S.; Kishimoto, Y.; Nagai, Y. Squid nerve sphingomyelin containing an unusual sphingoid base. J. Lipid Res. 41, 1118-1124(2000).

19. Bartke, N.; Fischbeck, A.; Humpf, H.-U. Analysis of sphingolipids in potatoes (Solanum tuberosum L.) and sweet potatoes (Ipomoea batatas (L.) Lam.) by reversed phase high-performance liquid chromatography electrospray ionization tandem mass spectrometry (HPLC-ESI-MS/MS). Mol. Nutr. Food Res. 50, 1201-1211 (2006).

20. Shaner R. L.; Allegood, J. C.; Park, H.; Wang, E.; Kelly, S.; Haynes, C. A.; Sullards, M. C.; Merrill, A. H., Jr. Quantitative analysis of sphingolipids for lipidomics using triple quadrupole and quadrupole linear ion trap mass spectrometers. J. Lipid Res. 50, 1692-1707 (2009).

21. Sugawara, T.; Kinoshita, M.; Ohnishi, M.; Nagata, J.; Saito, M. Digestion of maize sphingolipids in rats and uptake of sphingadienine by Caco-2 cells. J. Nutr. 133, 2777-2782 (2003).

22. Aida, K.; Takakuwa, N.; Kinoshita, M.; Sugawara, T.; 
Imai, H.; Ono, J.; Ohnishi, M. Properties and physiological effects of plant cerebroside species as functional lipids. in Advanced Research on Plant Lipids (Murata, N. ed.) Kluwer Academic Publishers. Netherlands, pp.233-236 (2003).

23. Takakuwa, N.; Kinoshita, M.; Oda, Y.; Ohnishi, M. Existence of cerebroside in Saccharomyces kluyveri and its related species. FEMS Yeast Res. 2, 533-538 (2002).

24. Takakuwa, N; Tanji, M.; Oda, Y.; Ohnishi, M. Distribution of 9-methyl sphingoid base in mushrooms and its effects on the fluidity of phospholipid liposomes. $J$. Oleo Sci. 51, 741-747(2002)

25. Sugawara, T.; Miyazawa, T. Separation and determination of glycolipids from edible plant sources by highperformance liquid chromatography and evaporative light-scattering detection. Lipids 34, 1231-1237 (1999).

26. Vesper, H.; Schmelz, E. M.; Nikolova-Karakashian, M. N.; Dillehay, D. L.; Lynch, D. V.; Merrill, A. H., Jr. Sphingolipids in food and the emerging importance of sphingolipids to nutrition. J. Nutr. 129, 1239-1250 (1999).
27. Yunoki, K.; Ogawa, T.; Ono, J.; Miyashita, R.; Aida, K.; Oda, Y.; Ohnishi, M.; Analysis of sphingolipid classes and their contents in meals. Biosci. Biotechnol. Biochem. 72, 222-225(2008).

28. Schmelz, E. M.; Crall, K. J.; Larocque, R.; Dillehay, D. L.; Merrill, A. H., Jr. Uptake and metabolism of sphingolipids in isolated intestinal loops of mice. J. Nutr. 124, 702-712 (1996).

29. Nyberg, L.; Nilsson, Å.; Lundgren, P.; Duan, R. D. Localization and capacity of sphingomyelin digestion in the rat intestinal tract. J. Nutr. Biochem. 8, 112-118 (1997).

30. Nilsson, A. Metabolism of sphingomyelin in the intestinal tract of the rat. Biochim. Biophys. Acta 64, 575-584 (1968).

31. Nilsson, A. Metabolism of cerebroside in the intestinal tract of the rat. Biochim. Biophys. Acta 87, 113-121 (1969).

32. Sugawara, T.; Kinoshita, M.; Ohnishi, M.; Tsuzuki, T.; Miyazawa T.; Nagata, J.; Hirata, T.; Saito, M. Efflux of sphingoid bases by P-glycoprotein in human intestinal Caco-2 cells. Biosci. Biotechnol. Biochem. 68, 2541-2546 (2004). 